\title{
ANALISIS KEKERASAN PADA REAR COVER TRANSMISION VOLVO A35E SETELAH PROSES REKONDISI MENGGUNAKAN METODE THERMAL SPRAY
}

\author{
Budha Maryanti dan Bahrul Akbar \\ Program Studi Teknik Mesin Fakultas Teknologi Industri \\ Universitas Balikpapan Telp. 0542-764205 \\ e-mail: budha_maryanti@yahoo.com
}

\begin{abstract}
Hardness is one of the mechanical properties of a material. The hardness of a material must be known especially for materials which in its use will be suppressed and friction. To know the hardness value of the material then do hardness test by using tool of hardness tester. One method used to increase the hardness of the material is by thermal spray method. Thermal Spray is a coating technology of both metal and non-metal materials that dispray on the base with the intention of providing protection against wear or recondition of the application so that back to the original function and size. The objective of this research is to know the result of hardness of transmission rear cover of PT 2509 VOLVO A35E after reconditioning. This research was carried out in May until June 2016. The research took place at PT.Intraco Penta Pima Service located in Manggar area of Balikpapan, East Kalimantan. The research object focused on the housing rear cover transmission of PT 2509 VOLVO A35 E which has been reconditioned with thermal spray method. In thermal spray, the material may be a powder, wire or rod and inserted into the flame of a spray gun. After the analysis, it is concluded that the hardness that occurs after the thermal spray process has changed which is about $30.88 \mathrm{HR}$ which previously was at $10.32 \mathrm{HR}$. Influence that occurs to the parent metal undergoing the process of reconditioning, which in the presence of the recondition process that occurs there will be a change in the nature of material hardness on the rear cover of $199 \%$.
\end{abstract}

Keywords: Rear cover transmission, thermal spray, and hardness.

\section{PENDAHULUAN}

Rear cover adalah komponen bagian dari transmisi yang terbuat dari material alumunium yang posisinya berada di bagian belakang transmisi yang berfungsi sebagai housing penghubung dan penerus putaran dari bagian belakang transmisi ke drop box, melengkapi poros output transmisi dan menahan seal oli belakang juga menyokong poros output. Rear cover dilengkapi dengan check point berfungsi untuk mengetahui pressure oli bagian belakang transmisi serta terdapat 2 sensor yang berfugsi untuk mengetahui putaran output shaft. Di rear cover juga terdapat comflange sebagai tempat penghubung propeller shaft [1].

Cara kerja rear cover adalah sebagai housing atau ruang dari transmisi akan berhubungan langsung dengan clutch K3, putaran dari clutch K3 diteruskan ke Dropbox melalui shaft sehingga putaran dari clutch K3 menjadi output bagi transmisi, rear cover sendiri mendapatkan pelumasan aliran fluida dari oil pump melalui saluran yang ada di dalam transmisi.

Material rear cover terbuat dari aluminium oleh sebab itu rear cover mempunyai kecenderungan sangat besar untuk mengalami keausan. Keausan pada rear cover dapat mengakibatkan turunnya kekuatan dan umur pakai serta stabilitas transmisi, juga mengurangi kemampuan serta mengurangi jaminan keamanan proses kerja transimisi dan umur pakai (life time).

Salah satu metode yang dapat digunakan untuk mengurangi keausan pada rear cover akibat gesekan antara seal dan housing adalah merekondisi bagian rear cover dengan metode thermal spray. Rumusan masalah pada penelitian ini yaitu, bagaimana kekerasan pada rear cover yang telah direkondisi menggunakan metode thermal spray.

Tujuan penelitian ini untuk mengetahui hasil kekerasan rear cover transmisi PT 2509 VOLVO A35E yang setelah direkondisi menggunakan metode thermal spray.

Thermal spray adalah suatu proses pelapisan dimana bahan baku dipanaskan dan diteteskan ke permukaan. Dalam thermal spray, material dapat berupa serbuk, kawat atau batang dan dimasukkan ke dalam flame yang dihasilkan spray gun, dimana material akan meleleh dan 
disemprot secara cepat menuju substrat yang akan dilapisi. Dengan maksud memberikan proteksi terhadap keausan ataupun rekondisi aplikasi sehingga kembali pada fungsi dan ukuran semula. Thermal spray dapat digambarkan sebagai gabungan/kombinasi antara pemanfaatan energi panas untuk pemanasan atau peleburan dan energi kinetik untuk mengalirkan dan mendispersikan leburan/lelehan yang di arahkan ke permukaan benda kerja. Energi panas dan kinetik dari nyala api dapat diproduksi dengan pembakaran campuran bahan bakar gas dan oksigen, atau dengan menggunakan sumber daya listrik [2].

Pelapisan thermal spray sering digunakan karena derajat kekerasan yang relative tinggi terhadap pelapisan cat. Untuk pelapisan logam dengan thermal spray kekerasan dan kepadatan lapisan tergantung pada bahan dan jenis peralatan thermal spray. Porositas lapisan tergantung juga pada proses dan bahan thermal spray.

\section{Pengujian Kekerasan}

Pengujian kekerasan dengan metode Rockwell bertujuan menentukan kekerasan suatu material dalam bentuk daya tahan material terhadap indentisasi dengan menggunakan indentor berupa bola baja ataupun kerucut intan yang ditekankan pada permukaan material uji tersebut. Pengambilan data menggunakan Rockwell superficial 15T ASTM E18 dikarenakan hanya ingin melihat kekerasan dari coating [3]. Untuk mempermudah analisa dan agar hasil pengujian valid maka dilakukan indentasi sebanyak 5 titik pada daerah top coat rear cover.

\section{Tempat dan Waktu Penelitian}

Penelitian dan pengambilan data dilakukan pada bulan Mei sampai Juni 2016 bertempat di PT. Intracopenta Prima Service, Tbk, Balikpapan, Kalimantan Timur.

\section{Variabel penelitian}

Penelitian ini menggunakan variabel, antara lain:

1. Variable bebas: titik uji kekerasan pada rear cover transmissi PT 2509 sebanyak 5 titik.

2. Variable terikat: pengujian yang digunakan bersifat pengujian mekanik dengan uji kekerasan.

3. Variable kontrol: wire yang digunakan adalah TSW-40J2 dengan diameter terluar $1.6 \mathrm{~mm}$ dan jarak semprotannya adalah $50-170 \mathrm{~mm}$.

\section{HASIL DAN PEMBAHASAN}

Pengujian kekerasan pada penelitian ini dilakukan di lima titik pada rear cover transmissi PT 2509 untuk mengetahui rata-rata kekerasan pada rear cover sebelum dan setelah direkondisi dengan menggunakan Rockwell hardness tester.

Pengujian kekerasan yang dilakukan untuk mengetahui distribusi kekerasan pada daerah top coat housing rear cover. Pengujian kekerasan menggunakan metode Rockwell.

\section{Hasil Pengujian Kekerasan}

Tabel 1. Hasil uji kekerasan rear cover sebelum proses thermal spray

\begin{tabular}{ccc}
\hline No & Titik uji kekerasan & HRC \\
\hline 1 & 1 & 10,3 \\
2 & 2 & 10,3 \\
3 & 3 & 10,4 \\
4 & 4 & 10,4 \\
5 & 5 & 10,2 \\
\hline
\end{tabular}




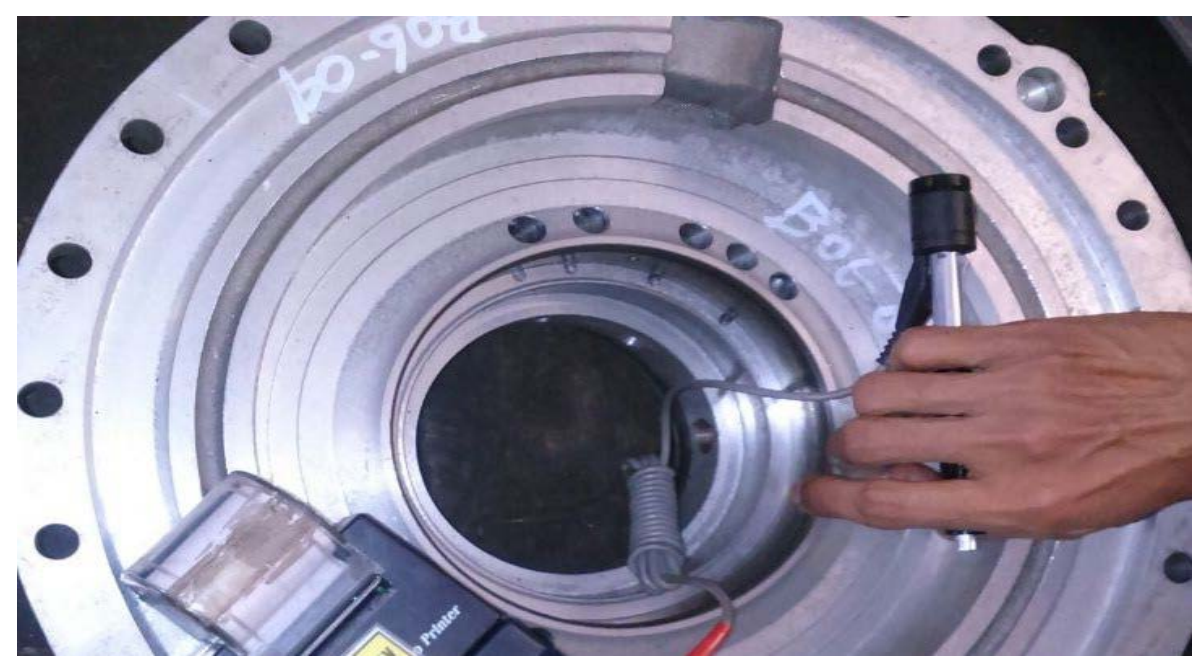

Gambar 1. Pengujian kekerasan rear cover sebelum thermal spray

Tabel 2. Hasil uji kekerasan rear cover setelah proses thermal spray

\begin{tabular}{ccc}
\hline No & Titik uji kekerasan & HRC \\
\hline 1 & 1 & 30,2 \\
2 & 2 & 30,3 \\
3 & 3 & 31,5 \\
4 & 4 & 31,6 \\
5 & 5 & 30,9 \\
\hline
\end{tabular}

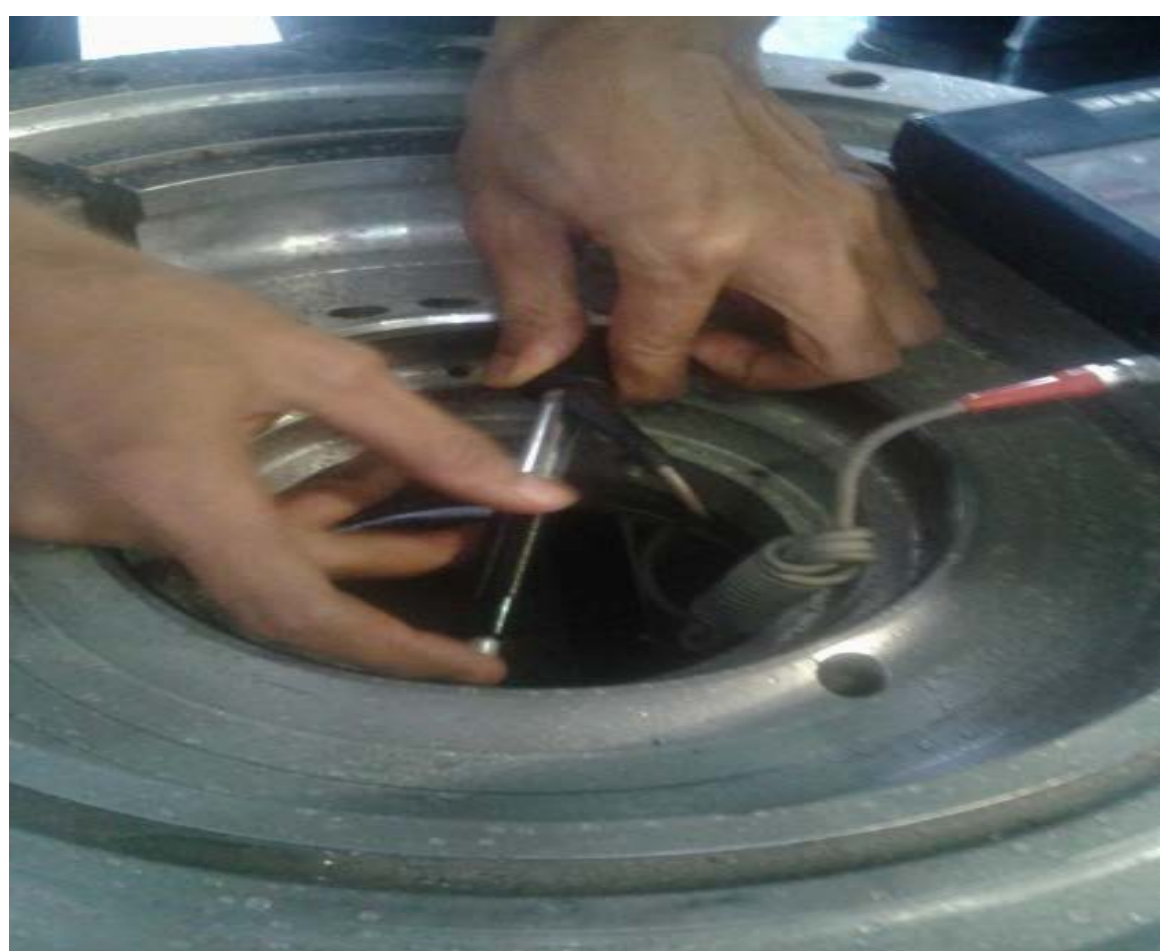

Gambar 2. Pengujian kekerasan rear cover setelah thermal spray

Dari hasil pengujian kekerasan terhadap rear cover tampak terjadi perubahan kekerasan rata-rata 30,88 HRC di daerah housing rear cover. Perubahan ini terjadi karena adanya pengaruh penambahan material rear cover dengan metode thermal spray secara garis besar memiliki pengaruh yang signifikan terhadap peningkatan kekerasan material pada rear cover. Kerapatan permukaan dan porositas coating berperan dalam meningkatkan nilai kekerasan. 


\section{Perbandingan Hasil Uji Kekerasan Rear Cover pada Transmissi PT 2509 Sebelum dan Sesudah Thermal Spray}

Tabel 3. Perbandingan nilai kekerasan sebelum dan sesudah proses thermal spray

\begin{tabular}{cccc}
\hline \multirow{2}{*}{ No } & \multirow{2}{*}{ Titik Pengujian } & \multicolumn{2}{c}{ Nilai Kekerasan HRC } \\
\cline { 3 - 4 } & & Sebelum rekondisi & Sesudah rekondisi \\
\hline 1 & 1 & 10,3 & 30,2 \\
2 & 2 & 10,3 & 30,3 \\
3 & 3 & 10,4 & 31,5 \\
4 & 4 & 10,4 & 31,6 \\
5 & 5 & 10,2 & 30,9 \\
\hline \multicolumn{2}{r}{ Nilai Rata-Rata } & 10,32 & 30,88 \\
\hline
\end{tabular}

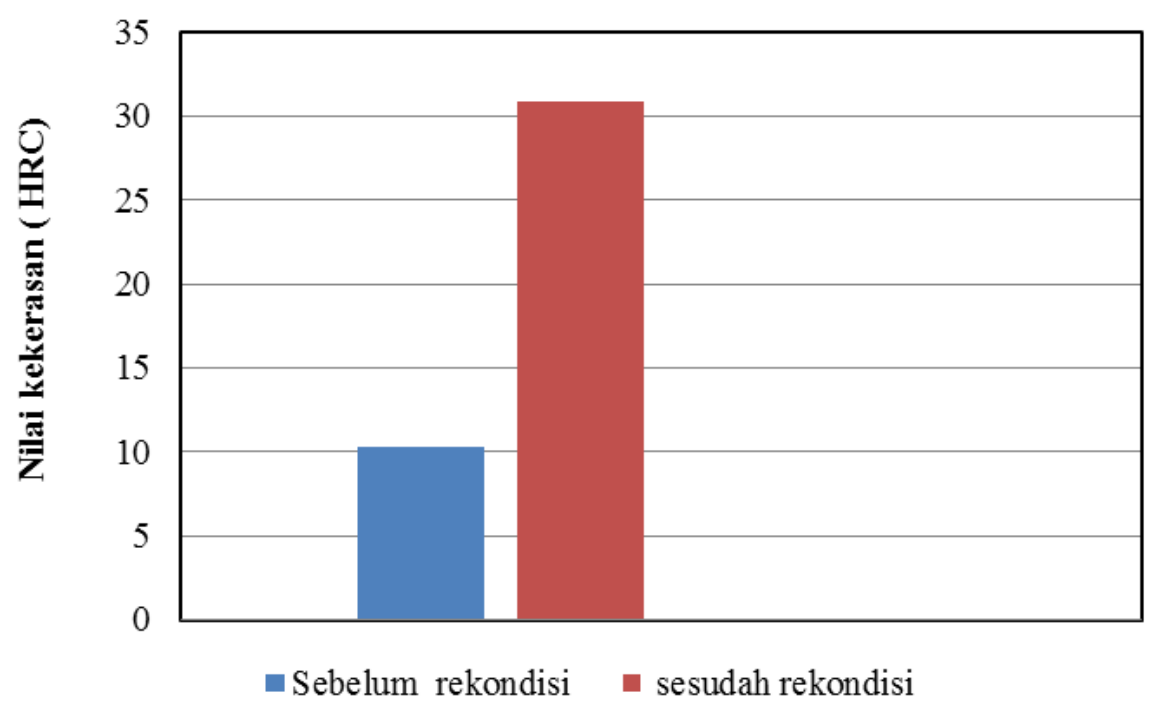

Gambar 3. Perbandingan nilai kekerasan rear cover sebelum dan sesudah thermal spray

Berdasarkan Tabel 3 dan Gambar 3, nilai kekerasan yang dihasilkan oleh rekondisi thermal spray memiliki nilai kekerasan yang lebih besar jika dirata-ratakan sebesar 30,88 HRC dibandingkan dengan nilai kekerasan sebelum rekondisi yang memiliki nilai kekerasan jika dirataratakan sebesar 10,32 HRC. Jika diprosentasekan kenaikan nilai kekerasan setelah proses thermal spray dirata-ratakan sebesar $199 \%$.

Keuntungan yang ditimbulkan dari rear cover yang sudah direkondisi:

a. Menggurangi keausan di rear cover yang terbuat dari bahan alumunium.

b. Life time transmissi lebih panjang dan mengurangi down time unit.

c. Menghemat waktu dan biaya transportasi untuk mendatangkan parts original.

\section{SIMPULAN}

Berdasarkan hasil data penelitian yang sudah dilakukan terhadap perubahan kekerasan di daerah rear cover pada transmission PT 2509 VOLVO A35E akibat proses rekondisi thermal spray dapat disimpulkan sebagai berikut: 1). Sebelum proses rekondisi pada rear cover pada transmission PT 2509 VOLVO A35E yang mengalami keasusan karena gesekan antara seal dan housing memiliki nilai rata-rata kekerasan dengan 10,32 HRC dan setelah proses rekondisi memiliki nilai rata-rata kekerasan sebesar 30,88 HRC. 2). Pengaruh yang terjadi terhadap logam induk yang mengalami proses rekondisi, dimana dengan adanya proses rekondisi yang terjadi akan ada perubahan sifat material pada rear cover sebesar 199\%. 


\section{DAFTAR PUSTAKA}

[1]. Anonim, 2015, Prosis Volvo construction equipment, PT. Intracopenta Prima Service, Tbk.

[2]. Sugiono Setiawan, Sugiono, Yuli Setiyorini, 2013, Pengaruh Variasi Sudut Nozzle Pada Arc Spray Coating terhadap Ketahanan Abrasif Lapisan 13\% Chrome Steel. Jurnal Teknik Pomits Vol. 2, No. 1, ISSN: 2337-3539, Fakultas Teknologi Industri ITS.

[3]. ASTM E18-00, 2000, Standard Test Methods for Rockwell Hardness and Rockwell Superficial Hardness of Metallic Materials, ASTM Committee, West Conshohocken, USA: ASTM International.

[4]. Asyari Daryus, 2012, Material Teknik, Teknik Mesin Universitas Darma Persada Jakarta.

[5]. Koswara, Engkos, 2010, Pengujian Logam, Humaniora Utama Pree Bandung, Bandung. 